\title{
RATING THE RESILIENCE OF TRANSPORT INFRASTRUCTURE PROJECT DELIVERY: THE CASE OF ROADS
}

\begin{abstract}
Transport infrastructure project delivery resilience has been defined and approached through the assessment of a project's likelihood to reach pre-specified performance targets. In this assessment, infrastructure project delivery is considered as a system and its key elements are represented through system indicators. Qualitative and quantitative (indicator) analysis of $86 \mathrm{EU}$ infrastructure projects allowed the identification of indicator combinations and their value ranges that capture the likelihood of achieving four key output targets, i.e. cost and time to construction completion; and actual vs forecast traffic and revenues. Indicators have also been classified as actionable (or not), i.e. allowing (or not) the possibility to improve the likelihood of reaching pre-specified project delivery targets. Based on indicator analysis findings, a novel methodology has been proposed for rating the likelihood of transport infrastructure projects to achieve their performance targets, through the use of the Transport Infrastructure Resilience Indicator (TIRESI). TIRESI ratings complement existing decision-support tools by indicating actions that may be taken to address identified vulnerabilities and improve project robustness. This paper takes stock of the TIRESI methodology and demonstrates the application of its rating system for the case of road infrastructure projects showing promising accuracy in its predictive power.
\end{abstract}

Keywords: Transport infrastructure, project delivery, resilience, rating system, decision-support tools, project management, roads \& highways 


\section{INTRODUCTION}

Successful project delivery has always been the quest of practitioners and researchers alike. To this end, factors influencing the potential of achieving project targets have been widely investigated resulting in several "prerequisites" that may not always be feasible and/or, in many cases, may even be mutually exclusive. Furthermore, many factors influencing project performance can and will change over the project delivery period. Such changes, whether internal or external to the project, add an additional layer of difficulty in attaining originally set targets. They also effectively highlight the existence of an issue of resilience in project delivery pertaining to how projects can withstand, adjust and recover from changes that may impact their performance and their ability to attain their delivery targets.

The assessment of resilience of infrastructure project delivery has been a rather elusive undertaking. Although extensive research has been conducted over past decades concerning factors influencing project performance (see for example Dolan et al, 2016; Carhart et al, 2016), three issues still need to be addressed: (i) which combinations of factors - as opposed to individual factors - influence which project outcomes; (ii) how much can factors change without impacting a project's potential to reach its targets; and (iii) which factors can decision makers and project managers act upon.

Existing project assessment systems concentrate mostly on the front-end of project delivery. Examples of such systems are the Project Definition Rating Index (PDRI), which pertains to the importance of front-endplanning (CCI, 1994; 2010); numerous rating systems that measure performance in terms of sustainability (cfr. Clevenger et al, 2013); as well as project creditworthiness ratings addressing issues of investment reliability with a particular emphasis on debt repayment (Pantelias and Roumboutsos, 2015). However, whilst it is widely known that the implementation phase of a project is central in achieving its outcomes (Polydoropoulou and Roumboutsos, 2009), it is also widely accepted that no tool is currently available that aims to capture the profile of this phase of project delivery and its impact on the likelihood of reaching prespecified project outcomes. A notable exception to this corresponds to applications of asset management 
systems and corresponding methodologies which tend, however, to be asset-specific and focus on a very specific part of project implementation and its outcomes (cfr. Adetola \& Goulding, 2016; Taggard et al, 2014; Shah et al, 2014).

The BENEFIT ${ }^{1}$ project, funded under the EU Horizon 2020 programme, addressed the above issues by developing the Transport Infrastructure Resilience Indicator (TIRESI) and its rating system as an additional, complementary decision-support tool for infrastructure project stakeholders. The TIRESI makes a contribution by filling an existing assessment gap, while exploiting the large body of knowledge on factors influencing project performance. This paper illustrates TIRESI methodology by applying it on road infrastructure projects.

The remainder of the paper is organised as follows: the background research undertaken within the BENEFIT project that led to the development of the Transport Infrastructure Resilience Indicator (TIRESI) is presented in the next section. The TIRESI and its corresponding rating methodology are then elaborated upon in section 3. In section 4, the methodology, is illustrated in more detail for the case of road infrastructure projects. The paper ends with a discussion and key conclusions as identified through the process of developing and applying the TIRESI methodology on road infrastructure projects with a look into the future.

\section{BACKGROUND}

\subsection{Infrastructure project delivery as a system: a bird's eye view}

In the context of the BENEFIT project, transport infrastructure project delivery is represented as a systemframework. The proposed system-framework receives inputs and generates outputs/outcomes while

\footnotetext{
${ }^{1}$ BENEFIT is the abbreviation of "Business Models for enhancing Funding and enabling Financing for Infrastructure in Transport", a project funded by the European Union Horizon 2020 research and innovation programme under grant agreement No 635973. For more information please look at: www.benefit4transport.eu
} 
considering a number of elements that influence transport infrastructure project delivery, as shown in Figure 1. The key elements of the system are: the implementation context; the business model; the funding scheme; the financing scheme; the contractual governance conditions of implementation; and, finally, the transport mode context.

\section{FIGURE 1 HERE}

FIGURE 1 Infrastructure Delivery System and Elements (Source: adapted from Roumboutsos, 2015)

In the proposed approach, system inputs and outcomes are explicitly defined (see Roumboutsos, 2015; Pantelias et al., 2015). The delivery of transport infrastructure projects is the result of a decision-making process that considers their objectives and development rationale ("raison d'être"), i.e. transport-related as well as wider policy goals, and define project technical characteristics (e.g. type of infrastructure, scale, size, materials, etc.), magnitude of investment, as well as the actual procurement model. These decisions are considered as input to the system and are assumed to be made in a rational way, supported by a vast body of research and knowledge (e.g. Cost -Benefit Analysis - CBA or multi-criteria decision analysis MCDA). Notably, in the adopted approach, non-rational or sub-optimal decisions will feature as system imbalances.

Furthermore, every transport infrastructure project produces outcomes: economic, environmental, societal, and institutional, among other potential categorisations. The attainment of these outcomes is central to the justification of the project as they are clearly related to the ability of the project to "deliver" its intended function(s) and fulfil the corresponding obligations and/or expectations. In BENEFIT, the systemframework is "operationalised" to address four specific outcomes. Two pertain to Project Management "iron triangle": cost and time to (construction) completion. The other two correspond to project operational goals, which are also considered in order to justify the investment: actual vs forecast traffic and revenues. The 
considered outcomes do not cover the entire range of transport infrastructure project outcomes (environmental, social, institutional etc.). However, they constitute the basis for the assessment of attainment of all other outcomes: the project has to be built and have traffic on it in order to generate any other outcome.

Finally, each outcome may be of different value to various project stakeholder groups. In this context, the work under the BENEFIT project did not seek to combine all outcomes in order to provide an assessment of "overall" project performance. The scope of research was to provide individual assessments per outcome and then allow individual stakeholders, depending on their own value system and/or interests, to assign weightings to them or take action(s) in order to favour the achievement of those outcomes that reflect their interests more strongly.

\subsection{Research concept, data and methodology}

Case-based analysis has been the primary tool employed by researchers to identify factors influencing the successful delivery of infrastructure projects, including transport infrastructure. The result of case-based research is the identification of factors influencing performance, which are, nonetheless, inevitably related to the context of the specific cases studied. It is, therefore, important not only to identify how combinations of factors influence project outcomes but also how to transfer findings from one context to the next. Roumboutsos (2015) proposed to address these issues through the representations of factors through corresponding indicators representing the infrastructure delivery system (Figure 1). Effectively, such indicators were developed in the context of the BENEFIT project in the form of numerical expressions of the factors influencing project delivery. Through them the infrastructure delivery system could be modelled providing decision-makers with a more comprehensible decision-support tool and enhancing the understanding of underlying trends and impacts. The resulting system indicators and their constituent parts 
were validated and calibrated during the course of the BENEFIT project and are presented in the following subsection.

The BENEFIT project case database constituted the basis of analysis. It includes 86 projects from 18 European countries covering all modes of transport infrastructure. In terms of their model of delivery, 55 are Public-Private Partnerships (PPPs) and 31 traditionally delivered public projects (a detailed description of the research dataset can be found at www.benefit4transport.eu as well as in Roumboutsos (2016); Roumboutsos et al. (2014); and Roumboutsos et al. (2013)) $)^{2}$. All information on these projects was sourced from the public domain which had positive and negative repercussions on the research undertaken. While the advantage was that the developed approach was unconstrained by the need for privileged and potentially commercially sensitive information, the drawbacks were a potential lack of accuracy and a resulting complication in the ability to generate indicators for all cases. In effect, only 56 cases could be represented in a numerical indicator format restricting the final sample used in the subsequent streams of analysis (see Table 1).

\section{TABLE 1 HERE}

\section{TABLE 1 Sample Summary}

As a start, an in-depth qualitative analysis of these cases was conducted per mode of transport, guided also by the structure of the system-framework (see Figure 1). Findings, i.e. factors identified to influence the achievement of outcomes, were compared with existing literature confirming, on the one hand, that the sample produced results which are comparable to other reported findings (and therefore, that the sample could be considered unbiased) and, on the other hand, the usability of the proposed representation (systemframework) as an analysis framework.

\footnotetext{
${ }^{2}$ This information is also available on the Benefit-wiki at www.benefit4transport.eu
} 
Then, project cases, were studied using quantitative analysis. To do so, data available at various points in each project's lifetime (e.g. planning, construction, inauguration, operation, etc.) was used to calculate corresponding sets of values of the system indicators thus enabling the generation of "snapshots" of project performance with respect to the four outcomes under investigation and their influencing factors. Through the generation of these time-related "snapshots" the dynamic nature of project delivery was also captured.

Three streams of analysis were subsequently conducted, introducing triangulation of analysis (see for example Jick, 1989): fuzzy-set Qualitative Comparative Analysis (fsQCA) (see Ragin (2008) for a description of the analysis method), Importance Analysis (Bayesian network analysis or Sensitivity Analysis; see Saltelli et al. (2008) for a description of the analysis method) and Econometric Analysis. The combination of all three analysis methods, produced a wealth of information allowing to identify combinations of indicators that would lead to the successful attainment of the four project outcomes under consideration. Based on the final sample size and the number of sets of indicator values ("snapshots") that could be constructed based on available information, the three analysis methods were applied on: (i) the entire sample (all modes); (ii) the entire sample split in cases before and after the Global Financial Crisis (GFC); (iii) PPP projects only (all modes); (iv) road projects only (PPP and traditional delivery); (v) road projects before and after the GFC (PPP and traditional delivery); (vi) PPP road projects only.

By identifying combinations of indicators and their respective threshold values as linked to different manifestations of the attainment of project outcomes at different points ("snapshots") of a project's lifetime, a rating system was developed as a tool to standardise the assessment and communication of project performance with respect to the attainment of such target outcomes. The resulting rating system is heuristic, in the sense that it learns from the consideration of different project cases, and yields an assessment of the likelihood of achieving specific target outcomes. Figure 2, below, outlines the methodology that was followed for the development of the rating system. The rating system and its characteristics are presented in more detail in section 3 of this paper, noting that differences exist per transport mode considered. 
FIGURE 2 HERE

\section{FIGURE 2 Methodology leading to TIRESI rating system}

\subsection{System indicators}

As mentioned earlier, a dynamic system's approach was adopted to map the interrelations of the transport infrastructure project delivery system elements influencing its functionality. The elements of the system were described by composite indicators, which were developed and validated (see Vanelslander and Roumboutsos, 2018) during the course of the BENEFIT project research. Notably, the dynamic nature of infrastructure project delivery is represented in the system through the consideration of different sets of values of these indicators at various points of a project's lifetime ("snapshots").

The process of developing the composite indicators followed a number of steps. Initially, a thorough review of the vast body of literature on factors influencing project delivery resulted in numerous relevant factors which were grouped/categorised under the system elements (see Figure 1). Then, from the multitude of factors initially identified per element, the ones to be finally included in the system and be represented by numerical indicators were determined through the application of appropriate research techniques (e.g. principal factor analysis, cluster analysis, etc.). The resulting indicators were validated against the qualitative analysis of project cases and subsequently used in all three streams of quantitative analysis. The final form and composition of each indicator and of the system-framework as whole was concluded following a number of iterations.

A brief presentation of the indicators representing each system element follows. 
The "Implementation context" element is described by two indicators: the Financial-Economic (FEI) and the Institutional (InI) indicator. The FEI measures more broadly the business environment and can be seen as a proxy of the level of productivity of a country. The InI shows the extent to which the political, legal and regulatory, and administrative context in a country is stable and mature. Both indicators are calculated using input from the World Bank Governance Indicators (WGI) and the OECD indicators of regulation in energy, transport and communications (ETCR), which are published annually for all countries.

The "Business Model" element is described by two composite indicators representing the two major parts of the business model, i.e. costs and revenues. The corresponding indicators also aim to capture conditions improving efficiency and effectiveness which essentially lead to Cost Saving and Revenue Support. Hence, the Cost Saving Indicator (CSI) illustrates the measure of a project's efficiency during construction and operation; and the Revenue Support Indicator (RSI) may be considered a measure of the project's ability to generate revenues, and, also, a measure of the project's efficiency in exploiting potential sources of revenue. More specifically, the CSI takes into account assessments of capability to construct, innovate and operate; life cycle planning; as well as an assessment of the optimality of risk allocation based on stakeholders' ability to manage the allocated risk. The maturity of the contracting authority to monitor the contract is also considered. Of particular interest is the emphasis placed on the project's exclusivity based on its position in the transport network (Roumboutsos and Pantelias, 2015). This is a sub-factor which is termed "Level of Coopetition" (LoC; the term "coopetition" was introduced in academic literature by Brandenburger and Nalebuff (1995) to describe the strategy of cooperation and competition in business). Both Business Model indicators are based on qualitative assessments. In order to avoid introducing biases in their calculation, qualitative assessments are supported and guided by a process of answering a series of relevant questions.

The "Governance" element is described by the composite Governance Indicator (GI), which refers to factors setting the governance scene within a project. The GI is a measure of the contractual governance efficiency and flexibility (see Cardenas et al, 2017) and is originally assessed at the award stage. The value of this 
indicator may change over time based on changes in contractual conditions (e.g. renegotiations or "silent" changes in agreed terms such as risk allocation creep). The indicator is calculated based on an objective assessment of the existence (or not) of particular features of the contract underpinning the project as well as the process through which is has been awarded.

The "Funding Scheme" element is described by two indicators: The Remuneration Attractiveness Indicator (RAI) and the Revenue Robustness Indicator (RRI). These indicators consider the project income and revenue streams weighted against the associated risks and are also cumulatively expressed as per the percentage (\%) of cost coverage they represent. The risks of income and revenue streams are related to the characteristics of the particular stream under consideration. In the calculation of the two indicators, specific levels of risks are assumed which can, however, be changed, if necessary, to reflect the circumstances of the specific project under consideration.

The "Financing Scheme" element is expressed through one indicator, the Financing Scheme Indicator (FSI), which is based on an expanded version of the weighted average cost of capital (WACC) of the project that is able to consider financing contributions from both public and private sources. Hence, in order to calculate the FSI the share of capital contributed from various sources and their expected returns (e.g. interest rates for debt capital) are required. Notably, FSI $=1$ denotes a traditionally procured project financed in full by state resources. On the opposite side of the spectrum, a project with FSI $=0$ is financed in full by the private sector receiving no guarantees or any other form of public support. When FSI takes values in the middle $(0<\mathrm{FSI}<1)$ a project may be financed by both public and private sources of capital. Interestingly, traditionally procured projects may have FSI $<1$ under particular conditions (e.g. when the state has issued debt guarantees, among other possible scenarios)

Finally, the "Transport Mode context" element is described with one indicator which is internal to the system, the Reliability-Availability Indicator (IRA). The indicator is calculated based on the observed or 
foreseen project reliability and availability. Notably, this element also comprises other project characteristics which are considered as initial input to the system and cannot be changed during implementation (e.g. infrastructure type, size of investment, etc.).

All described indicators take values in the continuous range [0,1], with values closer to the upper bound of the range $(\rightarrow 1)$ representing delivering the project with less risk and lower cost. The Cost Saving Indicator (CSI) is an exception as it takes values in the continuous range $[-0,333,1]$, its lower bound reflecting a purely negative effect of poorly structured projects.

\subsection{Findings}

An illustrative sample of findings pertaining to road infrastructure projects is presented per outcome in Table 2. Emphasis was placed on the assessment of project performance with respect to the Global Financial Crisis (GFC) (2007-2008) and its impact. All four streams of analysis (qualitative case study analysis, fuzzy-set qualitative comparative analysis, importance analysis and econometrics analysis) were compared and considered in a complementary fashion in order to provide guidelines with respect to the combination(s) of indicators and their respective (threshold) values required to achieve specific outcome targets per mode (Roumboutsos and Pantelias, 2018).

\section{TABLE 2 HERE}

\section{TABLE 2 Summary of indicators influencing outcomes in Road Infrastructure projects}

From Table 2, the following observations can be made:

- The Financial-Economic indicator (FEI), as expected, plays a significant role in road projects. An increase or decrease in the value of this indicator may have a respective impact on the probability of achieving Time to Completion, Cost to Completion, and Traffic targets. The influence is greater with 
respect to traffic and lower with respect to Time to Completion. A high value of the Institutional Indicator (InI) may off-set the impact of a low FEI on time targets. The FEI is not a determining indicator with respect to the revenue target. The influence of FEI in this case is introduced through the traffic achieved.

- The Institutional indicator (InI) may be the most important for road infrastructure. While exogenous to the project, it is not affected by economic cycles and, therefore, describes a measure of resilience to financial shocks. It is a pre-requisite in achieving Cost and Time to completion targets, while a high value may also limit the impact of a low FEI on attaining traffic targets. Once again, the InI is not a determining indicator with respect to the revenue target.

- The Governance indicator (GI) reflects in many ways the level of institutional maturity in the country where the project is procured. In this respect, it may compensate and/or enhance the InI. As it describes the institutional arrangements within the project, it practically influences all project outcomes.

- The Cost Saving indicator (CSI) describes the project's technical difficulty and also the capabilities of key project actors: the builders' to construct, the operator's to operate, and the contracting authority's to monitor the project in consideration. In addition, it assesses whether capabilities are aligned with the risk allocation among these actors. All these attributes were found to be important throughout the project life cycle. A high CSI may compensate for a lower value of GI with respect to cost to completion and may also contribute to off-setting the impact of a low FEI on traffic targets.

- The importance of the Revenue Support indicator (RSI) is limited in road projects and depends on the criticality and exclusivity of the project in the network. A high value of the factor "Level of Coopetition" (LoC), describing the exclusivity of the infrastructure in the transport network, may have a positive impact on cost to completion and revenue targets.

- The Remuneration Attractiveness Indicator (RAI) practically acts as a policy tool. Low values of the indicator will drive the attainment of time to completion targets. High values of the indicator will limit the effect of FEI on traffic and, also, support revenue targets. RAI creates incentives. 
- The Revenue Robustness Indicator (RRI) expresses the riskiness of the project revenue streams as well as the estimated level of cost coverage. Therefore, it becomes a key indicator in assessing the potential of achieving revenue targets and, also, drives the project towards being "on-time".

- The Financing Scheme Indicator (FSI) is also a policy tool as it becomes a response to adverse exogenous indicators. Low values of the FEI and InI dictate the need for higher values of the FSI. In other words, countries with low FEI and InI values are forced to increase public contributions to project financing structures or opt out of the PPP model for project delivery altogether.

The synthesis of findings per mode has led to the conclusion that each transport infrastructure mode is influenced differently by its implementation context and that different indicators contribute in each mode to the achievement of project outcome targets. Further consideration of the indicators and their contribution to the achievement of outcomes leads to their classification as exogenous and endogenous (see Figure 13 later in the article). Exogenous are indicators over which the project actors cannot act upon, while endogenous indicators may be considered actionable. More specifically, indicators exogenous to the project are:

- The Financial-Economic indicator (FEI). This is an important indicator, but does not have the same impact on all modes. Road projects are particularly sensitive to the FEI as it was found to influence all outcomes apart from revenues.

- The Institutional indicator ( $\mathrm{InI})$. This indicator has been identified as potentially the most important external indicator across all modes and for all outcomes. In many cases it was identified to be able to offset the impact of a low or decreasing FEI.

Indicators endogenous to the project are further divided into "Structural Indicators" and "Policy Indicators". The former reinforce project robustness, while the latter may be used in pursuit of trade-offs with respect to project outcomes, as they drive project outcomes differently depending on their values by creating corresponding incentives. This is a sharp contrast with respect to all other indicators for which, when important, low values are associated with low likelihood of achieving outcome targets. 
Structural indicators are:

- The Governance indicator (GI). This indicator reflects in many ways the level of institutional maturity in the country of project procurement and may compensate and/or enhance the InI.

- The Cost Saving indicator (CSI). This indicator was found to contribute to all outcomes and, in most cases, works in combination with GI. More specifically, it was found in many cases that a low value of the CSI could be offset by a higher value of GI and vice versa.

- The Revenue Support indicator (RSI). This indicator provides an indication of the level endorsement of alternative streams of revenues and the position of the infrastructure in the network. However, it is not always possible to have a high value and/or in many cases the projects are not designed for a high value of the RSI.

Policy indicators, i.e. those that may be used as a policy tool, are:

- The Remuneration Attractiveness Indicator (RAI). Demand-based remuneration schemes (low value of RAI) work well under positive exogenous conditions. In an adverse context, a low value of RAI needs to be supported by other indicators.

- The Revenue Robustness Indicator (RRI). This indicator expresses the riskiness of the project revenue streams as well as the estimated level of cost coverage.

- The Financing Scheme Indicator (FSI). It was observed that projects with high contributions of public sector support (high value of FSI) seek to achieve "on-budget" targets, while in cases where private financing is dominant (low FSI) there is an effort to predominantly achieve "on-time" targets. In addition, supporting project revenues lead to higher values of the FSI.

In summary, while the outcomes of transport infrastructure projects are influenced by certain factors that lie outside the managerial ability of the parties involved, there are many other internal project factors that may 
be modified to improve their potential of achieving expected outcome targets. This is an important input for the development of a resilience assessment methodology as it suggests that the resilience of project delivery could be improved by managing internal project parameters since external factors are not within the influence of project stakeholders.

\section{THE TRANSPORT INFRASTRUCTURE RESILIENCE INDICATOR (TIRESI) AND ITS RATING METHODOLOGY}

"Resilience" has been used as a "buzzword" in many scientific fields. In the context of infrastructure project delivery resilience can be associated with robustness, tolerance, flexibility, resourcefulness, adaptability, absorptivity, recoverability and many other similar attributes ((Rose, 2015; Bristow, 2015; Francis and Bekera, 2014; Shah et al, 2014; Rose and Krausmann, 2013; Filippini and Silva, 2013; Henry and RamirezMarquez, 2012; Montgomery et al, 2012; Hudson et al, 2012; Fisher et al., 2010; Bruneau et al., 2003). Such attributes may render a project successful through an assessment of the likelihood of attaining performance targets with respect to specific project outcomes and the specification of actions that can mitigate, enhance, or restore performance to originally expected levels.

Having identified combination(s) of indicators which increase the likelihood of attaining specific target outcomes enabled the development of a Transport Infrastructure Resilience Indicator (TIRESI) describing "the ability of a transport infrastructure project to withstand, adjust and recover from changes within its structural elements with respect to its ability to deliver specific outcomes (such as cost and time to completion, expected traffic and expected revenue targets)" (Roumboutsos and Pantelias, 2018).

This working definition guided the assessment of resilience towards an infrastructure mode-specific process, which also included a different specification of the threshold that defined "high" and "low" values for the indicators of each mode under consideration. The range of indicator values was calibrated for each mode 
and their reference "high" or "low" values assigned per level of likelihood and target outcome. This calibration was undertaken with the use of fuzzy set Qualitative Comparative Analysis (fsQCA) (Roumboutsos et al., 2016). Notably, calibration via fsQCA was based on mathematical operation as well as empirical observation (Ragin, 2008). Project case data observations in combination with the corresponding mode-specific qualitative analysis were used to determine the thresholds values per indicator, transport mode and outcome.

Based on the aforementioned definition of the TIRESI, a rating system was developed, which comprises three basic rating categories, namely A, B and C. These are specified as follows:

A: Describing very high likelihood of achieving a project outcome. Projects assigned an A rating exhibit high values for both exogenous (Financial-Economic (FEI) and Institutional (InI)) and endogenous (all other) indicators. The thresholds that determine whether indicator values for each infrastructure mode are "high" or not are specified separately.

B: Describing medium likelihood of achieving a project outcome. A project assigned a B rating exhibits potential vulnerability that may be due to either exogenous (FEI and InI) or endogenous (all other indicators) conditions. Because of these two different sources of vulnerability, this rating category is further divided into $\mathrm{B}_{\mathrm{EX}}$ and $\mathrm{B}_{\mathrm{EN}}$, corresponding to:

- Bex: A rating describing a fairly robust internal project structure but subject to exogenous vulnerability;

- B $_{\mathbf{E N}}$ : A rating describing a project implemented under largely positive exogenous conditions but with internal structure vulnerabilities.

C: Describing low likelihood of achieving a project outcome. Projects assigned a $\mathrm{C}$ rating are vulnerable to both exogenous and endogenous conditions. 
Furthermore, due to the many indicators involved in determining the rating for each outcome and mode, slightly better or worse conditions may exist. These are presented with additional rating notches, $(+)$ or (-) shown next to the basic rating, $\mathrm{A}, \mathrm{B}$ or $\mathrm{C}$.

Projects with a B rating are vulnerable to external shocks. The level of their vulnerability is associated with the potential deterioration (or improvement) in external conditions that may be needed for a project to change rating category (e.g. from $\mathrm{A}$ to $\mathrm{B}_{\mathrm{EX}}$ or vice versa). To this effect, a dynamic expression of the Transport Infrastructure Resilience Indicator was also introduced (D-TIRESI) expressing the percent (\%) decrease (or increase) in external conditions needed for the project outcome rating to change rating category. Therefore, the D-TIRESI is to be considered next to the initial rating, which is distinguished as "Static" (STIRESI) (Roumboutsos and Pantelias, 2018).

An important point to be made concerns the overall rating of the project. The TIRESI addresses separately the rating of each outcome. All outcomes are not influenced equally by the same indicators, and therefore an overall rating cannot be devised objectively. Considering this observation, the overall rating of the project may be assessed based on an individual stakeholder's value system and/or interest(s). Most commonly used approaches may refer to (among other possible ones):

- Identifying the "weakest link". In this case the outcome with the lowest rating would define the overall rating of the project.

- Assigning weights to each outcome and concluding on an overall weighted average. In this case, a stakeholder would assign weights reflecting their respective interests.

- A selective approach by which a stakeholder only considers the rating of the outcome they are interested in.

For example, a project at an early point of its lifetime ("snapshot") may be rated A with respect to cost to completion, $\mathrm{B}_{\mathrm{EX}}$ regarding time to completion, $\mathrm{C}$ concerning actual vs forecast traffic, and $\mathrm{B}_{\mathrm{EX}}$ with respect 
to its ability to achieve forecast revenues. A financier interested only in the project's ability to deliver on debt obligations during its operational life might consider this project with an overall rating $\mathrm{B}_{\mathrm{EX}}$, based on the revenue target rating. Under a more comprehensive assessment, the financier might also like to take account of the fact that the project will most probably be delivered "on budget" (A rating) or the fact that construction might be delayed ( $\mathrm{B}_{\mathrm{EX}}$ rating). In such a case, the financier would need to create a weighted average of the individual ratings for cost and time to completion and actual vs forecast revenues to reflect the overall project rating.

Following the development of the overarching TIRESI rating methodology, mode-specific methodologies addressing the rating of each mode and outcome were also developed (see Roumboutsos and Pantelias, 2018). All mode-specific methodologies are based on a heuristic approach which considers:

- The combined findings of indicator analyses for the mode under consideration (Table 2 presents the combined findings for road infrastructure);

- The identification of indicator threshold values for each mode and target outcome and, therefore, the specification of "high" and "low" indicator values;

- The ability to act in order to influence the attainment of outcome targets at different points in a project's life cycle.

More specifically, for each outcome target the indicators identified to influence performance are considered and introduced in a tree-type configuration in a sequential way, based on the ability of project stakeholders to act upon them and induce the desired change. Hence, each "tree" begins by considering threshold values of exogenous indicators which are the ones that cannot be influenced, i.e. the Financial-Economic Indicator (FEI) followed by the Institutional Indicator (InI). The Governance Indicator (GI) follows. The value of this indicator is set at the contract award stage. Changes introduced following award which have not been contractually foreseen will lead to deteriorating conditions and are usually avoided by managers. In addition, research findings showed that the GI may in many cases compensate for a smaller value of the InI. Notably, 
both indicators describe the institutional setting of the project, the former focusing on the exogenous part, while the latter on the endogenous. Then the influence of the Cost Saving Indicator (CSI) is considered. Again, many factors contributing to its value are set at project award such as the competence of the contracting authority and the contractors. This competence may improve or deteriorate over time. It was also found, however, that the CSI compensates for a low GI and, therefore, their effect is considered in combination. The Revenue Support Indicator (RSI), if influential, is then introduced. Some factors included in this indicator, such as the exclusivity of the project, are set at project design but may change over the life of the project. Finally, if influential, the last three indicators reflecting the remuneration scheme (RAI), the revenue scheme (RRI), and the financing scheme (FSI) are introduced. These last three indicators were found to drive specific outcomes depending on their values. In contrast to all other indicators, for which larger values tend to lead to more positive outcomes, RAI, RRI and FSI may lead to desirable outcomes when they take on smaller values.

\section{DETERMINING THE TRANSPORT INFRASTRUCTURE RESILIENCE INDICATOR FOR ROAD INFRASTRUCTURE PROJECTS}

In this paper, the TIRESI rating methodology was applied to 26 road projects in Europe and more specifically in Belgium (Via-Invest), Finland (E4 Helsinki-Lahti, E18 Muurla-Lohja), Greece (Attica Tollway, Central Greece (E65) Motorway, Elefsina-Korinthos-Patra-Pyrgos-Tsakona Motorway, Ionia Odos Motorway, Moreas Motorway), Italy (BreBeMi), The Netherlands (Combiplan Nijverdal), Norway (E39 Orkdalsvegen Public Road), Poland (A2 Motorway), Portugal (A22 and A23 Motorways), Serbia (Belgrade By-Pass Section A), Slovenia (A5 Maribor Pince Motorway, Koper-Izola Expressway), Spain (Radial 2, M-45, C-16 Terrasa Manresa toll motorway, Eje Aeropuerto (M-12) Motorway), and the UK (M25 Orbital, M-80, A-19 Dishforth, M6 Tollway). As may be observed, these projects have been implemented/operated over a broad range of time and under varying implementation conditions. Six (6) have been delivered through traditional public financing, 19 through various forms of PPP arrangements, 
while one (1) (C-16 Terrasa Manresa toll motorway) was built through public financing and its operation was tendered as a concession. Figures 3 to 6 show branches of the trees developed to assess the rating for cost-to-completion, time-to-completion and actual vs forecast traffic for these 26 road infrastructure projects. Trees are developed for all combinations of FEI and InI and more specifically for:

- $\quad$ FEI $>0.60$, which represents a high level of productivity;

- $\mathrm{FEI} \in[0.50,0.60)$;

- $\quad \mathrm{FEI}<0.50$, which represents a low level of productivity;

- $\operatorname{InI}>0.65$, indicating a mature institutional context;

- $\operatorname{InI} \in[0.60,0.65)$;

- $\operatorname{InI}<0.60$, indicating a poor institutional context.

FIGURE 3 HERE

FIGURE 3 Rating assessment for road infrastructure delivery for cost-to-completion when FEI $>0.60$ and $\operatorname{InI}>\mathbf{0 . 6 5}$

As demonstrated in Figure 3, a positive implementation context does not guarantee a positive rating (in this case for cost-to-completion). Given the values of other indicators describing project delivery, all ratings are possible ranging from $\mathrm{A}+$ to $\mathrm{C}-$.

FIGURE 4 HERE 
FIGURE 4 Rating assessment for road infrastructure delivery for cost-to-completion when FEI $>0.60$ and $0.60<\operatorname{InI}<0.65$

Lower values of the exogenous indicators do, however, have a negative impact on cost-to-completion targets as also identified in recent reports (see Ortega et al., 2015). Low values or a decrease in the original values of exogenous indicators may lead to cost overruns (see Figure 4). The GFC (2007-2008) has had such an effect on road projects. If the Institutional Indicator (InI), the Governance Indicator (GI) or even the Cost Saving Indicator (CSI) are high, the project may demonstrate relevant resilience. The Revenue Support Indicator (RSI) may provide a relevant incentive, otherwise support by low cost financing (FSI $\rightarrow 1$ or FSI $>0.60$ ) will be required to address budget overruns. For example, in many PPP road projects, the state might be required to provide additional support to the project through various forms of subsidies, guarantees or public financing.

FIGURE 5 HERE

FIGURE 5 Rating assessment for road infrastructure delivery for time-to-completion when $0.50<\mathrm{FEI}<0.60$ and $\operatorname{InI}>0.65$

Similar is the situation for time-to-completion. An incentive to complete on-time exists for higher risk remuneration schemes when private financing is involved (see Figure 5).

FIGURE 6 HERE

FIGURE 6 Rating assessment for road infrastructure delivery for actual vs forecast traffic when FEI $<0.50$ and $\operatorname{InI}>0.65$ 
Policy indicators (RAI, RRI and FSI) play a more important role in achieving forecast traffic volumes as well as revenue targets. However, these are supported and may reach their full potential under particular conditions of the Structural indicators.

The assessment of actual vs forecast revenues is somewhat different and is related to the traffic rating as shown in Table 3.

TABLE 3 HERE

TABLE 3 Rating A for road infrastructure delivery for actual vs forecast revenues

In order to validate the results of the TIRESI rating methodology, the predicted performance (as assessed through the ratings) of the 26 projects considered in this paper, was compared to their actual, observed project outcomes over time. The results of the comparison are shown in Figures 7-10.

FIGURE 7 HERE

\section{FIGURE 7 Cost-to-Completion as Rated and compared to observed outcome}

Figure 7 shows that 11 projects were rated $\mathrm{A}\left(\mathrm{A}^{+}, \mathrm{A}, \mathrm{A}-\right)$ at the award stage. Of these, nine (9) confirmed their rating by being either "on budget" or delivered "under budget". For those rated BEX or $\mathrm{B}_{\mathrm{EN}}$, the majority showed cost overruns, while those rated C performed better than expected.

FIGURE 8 HERE 


\section{FIGURE 8 Time-to-Completion as rated at award compared to observed outcome}

With respect to time-to-completion, of the 14 projects receiving an $\mathrm{A}(\mathrm{A}+, \mathrm{A}, \mathrm{A}-)$ rating at the award stage, 12 actually confirmed predictions. Similar are the results for those projects rated $\mathrm{B}_{\mathrm{EX}}, \mathrm{B}_{\mathrm{EN}}$ and $\mathrm{C}$.

FIGURE 9 HERE

FIGURE 9 Actual vs Forecast Traffic as rated at award compared to observed outcome

FIGURE 10 HERE

\section{FIGURE 10 Actual vs Forecast Traffic as rated after inauguration compared to observed outcome}

Ratings of the traffic outcome were assessed at two instances: at the award stage and following inauguration. Both ratings show a significant degree of accuracy with the one following inauguration being slightly better.

Figure 11 compares ratings at the award stage concerning the likelihood of achieving revenue targets. The large number of projects receiving (and achieving) an A rating is due to the consideration of project returns. In the case of publicly financed, delivered, and operated projects as well as for projects receiving availability fees, revenues are more or less guaranteed. In this context, Figure 12 which includes only projects with a demand-based remuneration scheme, is of greater interest presenting considerable accuracy of predictions. More specifically, of the eight (8) projects rated A (A+, A, A-), six (6) confirmed predictions by delivering as expected or better. The two (2) projects rated $\mathrm{B}_{\mathrm{EN}}$ and $\mathrm{C}$ failed to reach forecast revenues, while of the two (2) projects rated $\mathrm{B}_{\mathrm{EX}}$, one failed to reach its revenue target and the other over-performed, respectively.

\section{FIGURE 11 HERE}




\title{
FIGURE 11 Actual vs Forecast Revenues as rated at award compared to observed outcome
}

\author{
FIGURE 12 HERE
}

FIGURE 12 Actual vs Forecast Revenues as rated at award compared to observed outcome for demand based remuneration scheme PPP projects

The perusal of Figures 7 to 12 reveals that predictions are relatively accurate. However, it is also evident that at this initial stage of testing results are not uniform in terms of prediction quality. There might be a number of reasons for this including the fact that information for the estimation of the indicators has been collected from the public domain and, therefore, the observed discrepancy may be due to data accuracy limitations.

\section{DISCUSSION}

The development of the Transport Infrastructure Resilience Indicator (TIRESI) and its corresponding rating system are based on indicators describing the infrastructure delivery system. All indicators are objectively calculated either directly, based on relevant qualitative or quantitative data or indirectly, based on strictly guided qualitative assessments of project-related information found in the public domain. Indicator values may change throughout a project's lifetime reflecting changes in its internal and external conditions of implementation. However, most of the project's structuring decisions are made at the "front end" (e.g. planning, design, or procurement phase) based on anticipated (or predicted) project conditions and their expected fluctuations. Based on the proposed system representation, these conditions are reflected in specific indicator values at different points of a project's lifetime ("snapshots"). 
The value of the Governance indicator (GI) is set at the contract award stage. Improvements to contractual conditions may be made later in the project life-cycle but these will always be associated with negative impacts which would also be reflected on the GI. Moreover, an influential factor included in the GI relates to the level of competition for the project (number of bidders). In the case of re-negotiations, the GI indicator is automatically reduced as this factor is affected negatively (no competition as there is only one "bidder"). For example, a GI $=0.750$ at the start of the re-negotiations will automatically be reduced to GI $=0.700$ simply due to the fact that there is no competition. The Cost Saving Indicator (CSI) reflects the maturity of the project design and, also, the capabilities of the key delivery actors. Training will improve capabilities. The Revenue Support Indicator (RSI) includes the exclusivity of the infrastructure in the network, which may be improved or reduced depending on the influence of new infrastructure put in place and, also, the inclusion of other potential revenue streams. In some cases, additional streams of revenue may be included post-award (e.g. income from advertisements, energy generation, etc.) although the RSI value is generally set during planning and contract award. The Remuneration Scheme is set at contract award but may (theoretically) change throughout the life cycle of the project and this will also be reflected, along with the RSI, on the Revenue Robustness Indicator (RRI). The Financing Scheme indicator (FSI) is originally set at financial close. However, changes in the synthesis of the financing may take place during the entire project life-cycle provided that the necessary conditions and incentives are in place.

In effect, key conditions are "locked" at the contract award stage which will define the project's robustness. "Unlocking" (some or all of) them may not be completely impossible or might indeed be desirable to a certain extent under particular circumstances but will come at an increasingly high cost particularly in terms of transaction costs, as modifying contracts is expensive. Indeed, contract modifications (i.e. renegotiations) may be desirable due to changes in the project's implementation conditions over time that affect project delivery. For example, changes in exogenous indicators may be addressed by either improving Structural indicators or inducing incentives through Policy indicators. The former approach corresponds to increasing the project's internal structural robustness, while the latter describes the level at which the project may "re- 
bounce", following adverse effects from the external environment expressed through the FinancialEconomic (FEI) and Institutional (InI) indicators (see Figure 13). However, it should be stressed that changing structural indicators after contract award can be perilous. This is because some of them may be related to project processes that may not be repeated again in the same way, thus altering basic project structural characteristics (e.g. competition for the contract during the procurement process), with direct repercussions on new ratings. Policy indicators, on the other hand, present a lot more flexibility for changes throughout the project's lifetime, under specific conditions. However, their influence on project outcomes may not be as substantial as the influence of structural indicators which is why getting structural indicators right at the front end of projects is very important in determining the overall resilience of delivery.

Notably, all the above apply both to PPP and traditionally procured projects. However, there might be significant variations in some indicator values. The FEI and InI will not differ as these indicators describe the implementation context, which is exogenous to the projects and the model of delivery used. GI, CSI and RSI are related to actor competences and project structure. There might be equally competent (or less so) actors in both cases, even though contracting authorities might generally be considered more competent when monitoring traditionally procured projects. The same applies for the RAI and RRI indicators. A key differentiating indicator, as described earlier (see indicator descriptions), is the Financing Scheme indicator (FSI). In the case of the FSI, the indicator will reflect the specificities of the financing which may not be straightforward when the indicator takes values $0<\mathrm{FSI}<1$. Overall, however, the proposed methodological approach can be applied uniformly to both PPP and traditional procurement and is able to rate both types of projects based on their individual characteristics and not on the model of infrastructure delivery adopted.

FIGURE 13 HERE

FIGURE 13 Relational Illustration of Indicators over the Project Life-Cycle (Source: adapted from Roumboutsos and Pantelias, 2018) 
Based on the above observations, the TIRESI and its rating system can provide decision makers with useful information to assess the potential impact of changes on both internal and external project conditions. In cases where initial project arrangements are unable to withstand the effect of such changes, decisions makers can explore possible actions (by focusing on actionable indicators) which would allow projects to adjust and/or recover from corresponding performance shortfalls. Simply put, the TIRESI could serve as an additional tool for assessing the resilience of project delivery, facilitating the determination of relevant actions and their potential to improve (or not) the likelihood of reaching specific project goals. The TIRESI could therefore be useful on a number of different occasions. These include:

- The assessment of the corresponding costs and benefits of decisions made prior to project award with respect to the tendering conditions and the contractual agreement. For example, contracting authorities may be guided to include terms in contracts that would maximise CSI and GI, or organise the tendering process so as to maximise GI.

- The investigation of the impact of risk allocation decisions. Unsuitable risk allocation will not only result in high risk premiums and other additional costs to the project but may also limit the ability of the project to reach specific goals under adverse but sometimes also under normal exogenous conditions. When negotiating risk allocation, various reasons may result in risks not always being allocated based on the ability of each party to manage the allocated risk. Both parties (public and private) can now be made aware of the potential impact such decisions may have on the ability to reach project outcome targets.

- The marginal improvement (or not) of the likelihood of reaching project goals depending on the bundling of activities. Originally designed project structures might not be able to contribute to the expected results due to other controversial conditions in the transport infrastructure system (captured by and expressed through the indicators).

- The confirmation of the relative importance of the remuneration scheme and its composition in reaching projects targets and introducing incentives. This becomes particularly important in the face of increased 
uncertainty over project funding streams and exploring ways of securing additional revenues besides the ones generated by the transport service(s) provided by the infrastructure.

- Finally, the impact the financing scheme may have on reaching target outcomes. To this end, the Financing Scheme Indicator (FSI) becomes a useful policy tool as different (and potentially new) financing schemes may be expressed by it and their impact on project outcomes may be estimated or tested.

The above only constitute some of the potential applications of the TIRESI, which can also become a very useful tool during renegotiations when various project restructuring scenarios are examined. More specifically, the effectiveness of actions taken can be assessed based on the new TIRESI ratings that would result from the actions under consideration.

However, the most interesting attribute of the TIRESI is its ability to indicate actions that may be taken (if at all) to improve a project's ability to respond to adverse exogenous conditions. This complementarity lies in the TIRESI's capacity not only to indicate the project's ability to respond to obligations, but also to provide a measure of the potential reaction (and its feasibility), in cases where initial arrangements appear to be inadequate. Additional benefits of the approach are that the rating system is stakeholder-neutral and can be "customised" based on the particular interests of each participant.

Finally, the TIRESI can provide, in its current form, qualitative estimates of the likelihood of attaining targets that are relevant or important at different times (or phases) of a project's life cycle. A quantitative estimation of this likelihood cannot yet be made, as the methodology would need to be applied on a larger set of projects in order to elicit probability estimates. Nevertheless, it may still provide useful information and allow stakeholders to be involved in a project at different phases based on their interests as well as their inherent skills and capabilities. 


\section{CONCLUSIONS, LIMITATIONS AND FURTHER RESEARCH}

The ability of projects to "deliver" on their expected targets is critical when it comes to justifying their raison d'être and assessing their performance. A Transport Infrastructure Resilience Indicator (TIRESI) has been proposed with respect to project delivery accompanied by a corresponding rating methodology. The TIRESI aims to gauge the likelihood of attainment of four selected outcomes: Cost-to-(construction) Completion; Time-to-(construction) Completion; Actual vs Forecast Traffic; and Actual vs Forecast Revenues. Its assessment is based on a system of composite indicators describing the transport infrastructure delivery system over time. Exogenous indicators capture and reflect the impact of external changes and "shocks", such as a financial crisis. Endogenous indicators have been divided into "structural" and "policy". "Structural" indicators may define the initial robustness of the project. "Policy" indicators, allow for incentives to be introduced throughout the life-cycle of the project.

It is important to note that there is no single indicator or a specific group of indicators that are responsible for and/or could address all project outcomes. Successful project delivery many times involves a trade-off with respect to the achievement of specific outcomes and in this context, it is a field where conflicting interests are expected to be seen. To this end, the TIRESI methodology purposely avoids to propose an overall project rating that would be uniformly suitable for all project participants. This is left to each stakeholder to pursue by utilising the generated outcome-specific TIRESI ratings in a way that reflects their own perceived importance of reaching them.

Due to the way the TIRESI and its corresponding rating system have been developed, they may facilitate a better understanding of the robustness, the vulnerability, as well as the ability of initial arrangements and resources available to managers and other decision makers to address adverse external or internal changes to project implementation conditions. At the same time, they may allow stakeholders to seize opportunities that may improve the project's likelihood of reaching expected performance targets. 
Notwithstanding all the above perceived benefits from the development and use of the TIRESI rating methodology, the assessment of the resilience of project delivery is still not an easy undertaking. As demonstrated through this paper for the specific case of road infrastructure projects, a multitude of factors (in the form of composite indicators) and their threshold values appear to influence the likelihood of attaining specific outcome targets. This translates, in practical terms, to a high number of input values that a user of the methodology needs to provide in order to arrive at a project delivery resilience rating ${ }^{3}$. Furthermore, the underlying methodological framework is heuristic as the complexity of interactions of the identified factors is such that does not allow a more analytical approach. Elaborating the TIRESI and customising the rating methodology even for the case of road infrastructure projects involved a substantial research effort. Although the resulting rating accuracy is promising there is still a lot of room for improvement, not least by moving from qualitative assessments of likelihood to the elicitation of probabilities under each rating category. A substantially larger sample of projects would be required for this step forward, which also alludes to the corresponding larger data needs if the methodology is to be customised for other modes of transport or extended to other sectors of infrastructure (similarly encouraging preliminary results have been obtained for bridge/tunnel and urban transit (metro and tram) projects, cfr. Roumboutsos et al, (2018)). Last, but not least, access to more accurate and complete project information would clearly translate to additional improvements in the accuracy of the methodology and the precision of its application.

Overall, the TIRESI has been developed with the intention to fill an existing gap when it comes to the assessment of resilience of project delivery. The present paper presents findings and illustrates the

\footnotetext{
${ }^{3}$ To facilitate the rating assessment, the TIRESI rating system is supported by a user-friendly web-based assessment tool that computes the system indicators as well as the various performance ratings based on information provided by the user. For more information on the application please visit: http://www.tiresias-online.com/benefit/.
} 
methodology in detail for the case of road infrastructure projects under varying conditions of implementation and for various project structures, yielding predictions with a good level of accuracy. Although further research is required in order to improve the methodology and expand it to other modes of transport or sectors of infrastructure, the proposed approach has shown a viable way towards the systematic assessment of resilience of project delivery.

\section{ACKNOWLEDGEMENTS}

The contents of this paper are partly based on research carried out within the framework of the BENEFIT (Business Models for enhancing Funding and enabling Financing for Infrastructure in Transport) project. The BENEFIT project has received funding from the European Union's Horizon 2020 research and innovation programme under grant agreement No 635973.

\section{REFERENCES}

Adetola, A. and Goulding, J. (2016), Collaborative framework for road infrastructure management, Infrastructure Asset Management, 3(2): 71-80

Bradenburger, A.M. and Nalebuff, B.J. (1995), The right game: use game theory to shape strategy, Harvard Business Review, 73(4): 57-71

Bristow, D.N. (2015), Asset system of systems resilience planning: the Toronto case, Infrastructure Asset Management, 2(1): 15-22

Bruneau, M., Chang, S., Eguchi, R., Lee, G., O’Rourke, T., Reinhorn, A., Shinozuka, M., Tierney, K., Wallace, W. and von Winterfeldt, D. (2003), A Framework to Quantitatively Assess and Enhance Seismic Resilience of Communities, Earthquake Spectra, 19(4): 733-752 
Cardenas, I.C., Voordijk, H., and Dewulf, G. (2017), Beyond theory: Towards a probabilistic causation model to support project governance in infrastructure projects, International Journal of Project Management, 35(3): 432-450

Carhart, N.J., Bouch, C., Walsh, C.L., and Dolan, T. (2016), Applying a new concept for strategic performance indicators, Infrastructure Asset Management, 3(4): 143-153

CII (Construction Industry Institute) (1994), Pre-project planning: Beginning a project the right way, Austin, TX

CII (Construction Industry Institute) (2010), PDRI: Project definition rating index for infrastructure projects, Austin, TX

Clevenger, C., Ozbek, M.E. and Simpson, S. (2013), Review of Sustainability Rating Systems used for Infrastructure Projects, Associated Schools of Construction, 49 ${ }^{\text {th }}$ ASC Annual International Conference Proceedings

Dolan, T., Walsh, C.L., Bouch, C., and Carhart, N.J. (2016), A conceptual approach to strategic performance indicators, Infrastructure Asset Management, 3(4): 132-142

Filippini, R. and Silva, A. (2014), A Modeling Framework for the Resilience Analysis of Networked Systems-of-Systems Based on Functional Dependencies, Reliability Engineering and System Safety, 125: $82-91$ 
Fisher, R.W., Bassett, G.W., Buchring, W.A., Collins, M.J., Dickinson, D.C., Eaton, L.K., et al (2010), Constructing a Resilience Index for the Enhanced Critical Infrastructure Protection Program, Report ANL/DIS-10-9, Argonne National Laboratory

Francis, R. and Bekera, B. (2014), A Metric and Frameworks for Resilience Analysis of Engineered and Infrastructure Systems, Reliability Engineering and System Safety, 121: 90-103

Henry, D. and Ramirez-Marquez, J.E. (2012), Generic Metrics and Quantitative Approaches for System Resilience as a Function of Time, Reliability Engineering and System Safety, 99: 114-122

Hudson, S., Cormie, D., Tufton, E., and Inglis, S. (2012), Engineering resilient infrastructure, Proceedings of the Institution of Civil Engineers, 6: 5-12

Jick, T.D. (1979), Mixing Qualitative and Quantitative Methods: Triangulation in Action, Administrative Science Quarterly, Qualitative Methodology, 24(4): 602-611

Montgomery, M., Broyd, T., Cornell, S., Pearce, O., Pocock, D., and Young, K. (2012), An innovative approach for improving infrastructure resilience, Proceedings of the Institution of Civil Engineers, 6: 27-32

Ortega, A., Baeza, M. \& Vassallo, J.M. (2016), Contractual PPPs for Transport Infrastructure in Spain: Lessons from the Economic Recession, Transport Reviews, 36(2): 187-206

Pantelias, A. and Roumboutsos, A. (2015), A Conceptual Framework for Transport Infrastructure PPP Project Credit Assessments, Journal of Finance and Economics, 3 (6): 105-111 
Pantelias, A. and Roumboutsos, A. (2018), Investing in Transport Infrastructure: A stakeholder's view, in Roumboutsos, A., Voordijk, H. and Pantelias, A. (Eds.), Funding and Financing Transport Infrastructure: Business Models to Enhance and Enable Financing of Infrastructure in Transport, Routledge, Taylor and Francis Group, ISBN 9781138293892 , Abingdon, UK

Pantelias, A., Roumboutsos, A., Bernardino, J., Bonvino, G., Cardenas, I., Dimitriou, H., Karadimitriou, N., Karousos, I., Kolahi, A., Mitusch, K., Moraiti, P., Moschouli, E., Trujillo, L., Vajdic, N., Vanelslander, T., Verhoest, K., Voordijk, H., Willems, T., Wright, P. (2015), Deliverable D3.1 - Methodological Framework for Ex-Post Analysis, BENEFIT (Business Models for enhancing Funding and enabling Financing for Infrastructure in Transport) Horizon 2020 project, grant agreement No 635973. Available at http://www.benefit4transport.eu/index.php/reports

Polydoropoulou, A. and Roumboutsos, A. (2009), Evaluating the impact of decision making during construction on transport project outcome, Evaluation and Program Planning, 32(4): 369-380

Ragin, C.C. (2008), Redesigning Social Inquiry - Fuzzy Set and Beyond, The University of Chicago Press: Chicago \& London.

Rose, A. (2015), Measuring Economic Resilience: Recent Advances and Future Priorities, Conference on "Effective Corporate Leadership and Governance Practices in Catastrophe Risk Management”, Wharton School, University of Pennsylvania

Rose, A. and Krausmann, E. (2013), An Economic Framework for the Development of a Resilience Index for Business Recovery, International Journal of Disaster Risk Reduction, 5: 73-83 
Roumboutsos, A. (2015), Case Studies in Transport Public-Private Partnerships: Transferring Lessons Learned, Transportation Research Record: Journal of the Transportation Research Board, 2530: 26-35

Roumboutsos, A. (2016), E-BOOK: Business Models for enhancing funding and enabling financing for infrastructure in transport: PPP and Public Transport Infrastructure Financing Case Studies, Horizon 2020 European Commission. Department of Shipping, Trade and Transport, University of the Aegean, Greece, ISBN 978-618-82078-1-3

Roumboutsos, A., Farrell, S., Liyanage, C.L. and Macário, R. (2013), COST Action TU1001 Public Private Partnerships in Transport: Trends \& Theory P3T3, 2013 Discussion Papers Part II Case Studies, ISBN 978-88-97781-61-5

Roumboutsos, A., Farrell, S., and Verhoest, K. (2014), COST Action TU1001 - Public Private Partnerships in Transport: Trends \& Theory: 2014 Discussion Series: Country Profiles \& Case Studies; ISBN 978-886922-009-8

Roumboutsos, A, and Pantelias, A. (2015), Allocating revenue risk in transport infrastructure PPP projects: how it matters, Transport Reviews, 35(2): 183-203

Roumboutsos, A. and Pantelias, A. (2018), Measuring Transport Infrastructure Project Resilience, in Roumboutsos, A., Voordijk, H. and Pantelias, A. (Eds.), Funding and Financing Transport Infrastructure: Business Models to Enhance and Enable Financing of Infrastructure in Transport, Routledge, Taylor and Francis Group, ISBN 9781138293892, Abingdon, UK

Roumboutsos, A., Pantelias, A., Sfakianakis, E., Edkins, A., Karousos, I., Konstantinipoulos, E., Leviäkangas, P., Moraiti, P. (2016), Deliverable D3.2- The Decision Matching Framework Policy Guiding 
Tool, Project Rating Methodology and Methodological Framework to increase business model creditworthiness, BENEFIT (Business Models for enhancing Funding and enabling Financing for Infrastructure in Transport) Horizon 2020 project, grant agreement No 635973. Available at http://www.benefit4transport.eu/index.php/reports.

Saltelli, A., Ratto, M., Andres, T., Campolongo, F., Cariboni, J., Gatelli, D. Saisana, M., and Tarantola, S. (2008), Global Sensitivity Analysis, The Primer, John Wiley \& Sons

Shah, J., Jefferson, I., and Hunt, D. (2014), Resilience assessment for geotechnical infrastructure assets, Infrastructure Asset Management, 1(4): 95-104

Taggart, A., Tachtsi, L., Lugg, M., and Davies, H. (2014), UKRLG framework for highway infrastructure asset management, Infrastructure Asset Management, 1(1): 10-19

Vanelslander, T. and Roumboutsos, A. (2018), Transport Infrastructure Delivery in Context, in Roumboutsos, A., Voordijk, H. and Pantelias, A. (Eds.), Funding and Financing Transport Infrastructure: Business Models to Enhance and Enable Financing of Infrastructure in Transport, Routledge, Taylor and Francis Group, ISBN 9781138293892, Abingdon, UK

Wiki BENEFIT, www.benefit4transport.eu 